\title{
An ethical and prudential argument for prioritizing the reduction of parasite-stress in the allocation of health care resources
}

\author{
doi:10.1017/S0140525X11001026 \\ Russell Powell, Steve Clarke, and Julian Savulescu \\ Science and Religious Conflict Project, Oxford Uehiro Centre for Practical \\ Ethics and Institute for Science and Ethics, Oxford Martin School and Faculty of \\ Philosophy, University of Oxford, Oxford OX1-1PT, United Kingdom. \\ russell.powell@philosophy.ox.ac.uk \\ stephen.clarke@philosophy.ox.ac.uk \\ julian.savulescu@philosophy.ox.ac.uk \\ http://www.practicalethics.ox.ac.uk/staff \\ http://www.src.ox.ac.uk/staff.htm
}

\begin{abstract}
The link between parasite-stress and complex psychological dispositions implies that the social, political, and economic benefits likely to flow from public health interventions that reduce rates of nonzoonotic infectious disease are far greater than have traditionally been thought. We sketch a prudential and ethical argument for increasing public health resources globally and redistributing these to focus on the alleviation of parasite-stress in human populations.
\end{abstract}

If Fincher \& Thornhill's (F\&T's) thesis is correct, there should be significant changes to the priorities of global health institutions, as well as a substantial increase in the overall global investment in health care. The link between parasite-stress and complex social psychological dispositions implies that the ethical, social, economic, and political benefits that are likely to flow from public health interventions that reduce rates of non-zoonotic/multi-host infectious disease are far greater than have traditionally been thought. These include not only immediate health benefits to afflicted individuals and averted medical costs due to reduced rates of infection, but also the ontogenetic production of personality configurations that promote democratic values and could lead to a significant reduction of intergroup conflicts and human rights violations worldwide within a short time frame. Here, we sketch a prudential and ethical argument for increasing public health resources globally and redistributing these to focus research and development efforts on the alleviation of parasite-stress in human populations.

The dominant approach to the evaluation of health care policy is cost-effectiveness analysis, which compares the cost of biomedical interventions with their medical efficacy (Beauchamp \& Childress 2001). This narrow focus on illness, averted medical costs, and other health-related impacts has caused policy makers to underestimate the expected utility of many public health interventions. A growing body of research indicates that the well-established causal pathway from higher income to better health also runs in the opposite direction, with health underwriting economic development through its effects on labor productivity, fertility rates, education, and cognitive development (Bloom \& Canning 2000). The impact of public health on economic growth has been demonstrated for the use of antibiotics, antimicrobials, vaccination, sanitation measures, and vector reduction (Bloom et al. 2005; Hotez et al. 2006). 
However, if F\&T's thesis is correct, then infectious diseaserelated interventions are likely to have more far-reaching social, economic, and political implications. It is well known that societal choices can affect susceptibilities to infectious disease, but few have imagined a proximate causal pathway through which infectious disease can shape sociopolitical choices. The authors have identified such a pathway, one mediated by adaptively plastic social psychological mechanisms that are contingent on environmental cues of parasite-stress. These cues trigger mechanisms of in-group assortative sociality that lead to the ontogenetic production of personality configurations associated with a particular range of political psychologies and organizations. Dispositions toward ethnocentricism, xenophobia, distrust, derogation, intolerance, and hostility towards out-group members act to buttress authoritarian political institutions and reinforce gender inequalities and racial hierarchies. Such non-egalitarian attitudes impede the development of liberal democratic institutions and breed antagonistic intergroup relations that can spawn large-scale human rights violations (Hewstone et al. 2002), with consequent political and economic instability. The rhetoric of dehumanization that often accompanies bouts of ethnic cleansing and genocide strategically plays on the disgust-modulated operation of the behavioral immune system, with out-group members frequently compared to rats, cockroaches, lice, or other disease vectors (Navarrete \& Fessler 2006).

All major conceptions of morality and justice view impartiality as a core moral ideal (Hauser 2006). Moral progress since the Enlightenment is characterized by an expanding circle of moral concern encompassing not just members of one's ethnic, political, or religious group, but also wider humanity and even some nonhuman animals (Singer 1981). The principle of equality that drives this moral expansion underpins the liberal political institutions that characterize modern constitutional democracy and the rule of law. It requires that individuals be treated equally and be afforded the same basic rights, privileges, and access to social resources. Perhaps the greatest challenge to implementing the impartial moral standpoint comes from strong biopsychological dispositions toward in-group partiality and out-group apathy or antagonism, which create a social-psychological climate in which it is difficult for democratic values and institutions to take root. Moreover, solving the most pressing problems of the 21 st century, including global poverty, climate change, and terrorism, will require enhanced levels of intergroup cooperation that historically have been hampered by the restricted altruism and negative intergroup dispositions that characterize strong assortative sociality. We therefore have weighty moral, prudential, and economic reasons for altering ecological conditions that are conducive to the acquisition and perpetuation of such biases, and for assigning these interventions a high priority in the allocation of scarce resources.

The question of how to distribute limited medical resources is a question of distributive justice, of which there are various theories. According to utilitarianism, resources should be distributed so as to maximize utility, where utility is measured in terms of happiness, preference satisfaction, or some objective measure of well-being (Bykvist 2010). From a utilitarian standpoint, the moral imperative to dedicate more resources to alleviating parasite-stress is straightforward, given that the expected utility of such interventions clearly outweighs their cost even on narrow views of the benefits (Hotez et al. 2006; Lee et al. 2011). Another dominant theory, liberal egalitarianism, prioritizes individuals in greatest need of the resources being distributed (Rawls 1971). This philosophical tradition widely regards basic healthcare as a fundamental human need, the moral force of which is amplified by the impact of health on economic growth, social justice, and the development of liberal political institutions. Even if one thinks that physicians should focus exclusively on the medical interests of their patients for professional reasons, it is appropriate that governments, international health organizations and funding bodies take these non-health-related impact factors into consideration and reform the narrowly defined methods by which they evaluate proposed health care interventions.

The fact that the postulated psychological mechanism is phenotypically plastic and sensitive to specific environmental cues implies that it is highly amenable to intervention. Reducing rates of non-zoonotic infectious disease will result in a corresponding reduction of in-group assortative sociality and its consequent sociopolitical benefits within a reasonably short timeframe. Altering the ecological conditions that seed social injustice and intergroup conflict is of the foremost ethical concern. If ingroup assortative sociality is, like fever or inflammation, an adaptive strategic defense against infection, then rather than merely treating the symptom we have strong moral reasons to eliminate its root cause.

\section{ACKNOWLEDGMENT}

Preparation of this commentary was supported by Arts and Humanities Research Council Standard Grant AH/F019513/1. 